Research Article

\title{
Biopsychosocial Wellbeing of High-Risk Pregnant Women: A Descriptive Study
}

\author{
Taniya Bera', Sonia R B D'Souza' ${ }^{2}$, Sushmitha Karkada ${ }^{3}$
}

${ }^{1}$ Assistant Professor, Apollo Gleneagles Nursing College, RGN/6/A/S/1044, Narayanpur, Battala, Kolkata, West Bengal, India. ${ }^{2}$ Associate Professor, ${ }^{3}$ Assistant Professor, Manipal College of Nursing, Manipal University, Manipal, Udupi, Karnataka, India. DOI: https://doi.org/10.24321/2455.9318.201931

\section{I $\quad \mathbf{N} \quad \mathbf{F} \quad \mathbf{O}$}

\section{Corresponding Author:}

Taniya Bera, Apollo Gleneagles Nursing College, RGN/6/A/S/1044, Narayanpur, Battala, Kolkata, West Bengal, India.

E-mail Id:

taniya.bera27@gmail.com

Orcid Id:

https://orcid.org/0000-0003-1064-7054

How to cite this article:

Bera T, D'Souza SRB, Karkada S. Biopsychosocial Wellbeing of High-Risk Pregnant Women: A Descriptive Study. Int J Nurs Midwif Res 2019; 6(4): 39-43.

Date of Submission: 2019-12-14

Date of Acceptance: 2020-02-18

\section{$\begin{array}{llllllllllllll}\text { A } & \text { B } & \mathbf{S} & \mathbf{T} & \mathbf{R} & \mathbf{A} & \mathbf{C} & \mathbf{T}\end{array}$}

Introduction: According to a recent study in India, perinatal mortality and morbidity score is high and high-risk is one of the most leading cause. All the antenatal women should be assessed for the risk factors like maternal age, reproductive history, the previous still birth, neonatal deaths, congenital anomalies, grand multiparty, anaemia, previous preterm, preeclampsia, previous caesarean, $\mathrm{Rh}$-isoimmunisation, $\mathrm{ABO}$ incompatibility, medical diseases like diabetes, renal diseases, pulmonary diseases, family history of diabetes, hypertension and congenital malformations.

Aim: The present study aimed to determine the biopsychosocial wellbeing and find out relation between biological, psychological and social wellbeing of high-risk pregnant women.

Material and Methods: This study utilized a survey approach with a descriptive study design and was conducted in selected private hospitals in Udupi district, Karnataka. A total of 303 women with high-risk pregnancy after 28 weeks of gestation, attending Obstetrics and Gynaecology OPDs and who were admitted in the antenatal wards, were selected by using non- probability purposive sampling technique. Descriptive (Frequency and percentage) and Inferential statistics (Spearman's $\rho$ ) was used to analyse the data.

Result: The prevalence of low biological wellbeing was found to be 161 (53.1\%), low psychological wellbeing $148(48.8 \%)$, high psychological wellbeing, low social wellbeing $172(56.76 \%)$ among 303 highrisk pregnant women more than 28 weeks of gestation. There was statistically significant relationship between biological and psychological wellbeing (Spearman $\rho=0.56, p=<0.000$ ): biological and social wellbeing (Spearman's $\rho=0.245, \mathrm{p}=<0.000$ ); social and psychological wellbeing (Spearman $\rho=0.391, \mathrm{p}=<0.000$ ).

Conclusion: The present study concluded that majority of high-risk pregnant women had low bio-psychosocial wellbeing and had significant relation in between biological, psychological and social wellbeing which may help health care workers to contribute a need-based quality care and help to improve the outcome of pregnancy.

Keywords: High-Risk Pregnancy, Biological Wellbeing, Psychological Wellbeing, Social Wellbeing 


\section{Introduction}

The World Health Organization report recently published that the major complication that occurs for nearly $75 \%$ of all maternal deaths are severe bleeding, infections, high blood pressure, complications for delivery and unsafe abortion.

Recent advances in modern Obstetrics and Neonatal care in India is still facing high perinatal mortality rate (33/1000 live births). ${ }^{1}$

A prospective study stated that a high-risk condition during pregnancy is one of the causative factors and had a significant risk for both maternal and foetal morbidity and mortality. Result revealed that, among 405 pregnant women, 96 (59\%) were high-risk, 191 (46\%) were low risk, 128 (31\%) were having no risk. ${ }^{2}$

An analytical study stated that pregnancy bring about physiological changes that may lead to high-risk pregnancy. Among 1266 pregnant women, result revealed that 804 $(63.5 \%)$ were having high-risk pregnancy and 462 (36.5\%) were having low risk pregnancies. There were high-risk pregnancy chances more in nullipara $(R R=0.646,95 \% \mathrm{Cl}$ 0.59-0.70) than low risk group and also high-risk pregnancy chances more among $\leq 18$ years or $\geq 35$ years age group (OR=0.417, 95\% $\mathrm{Cl}: 0.319-0.545 ; \mathrm{p}=0.000$ ) than between 18-35 years age group. ${ }^{3}$

\section{Materials and Methods}

This was a hospital-based survey, a non-experimental descriptive study conducted at selected hospitals of Udupi district, Karnataka between $6^{\text {th }}$ January to $6^{\text {th }}$ February, 2016.

Total 303 high-risk pregnant women were selected by using non-probability purposive sampling technique, fulfilling inclusion criteria such as high-risk pregnant women who were: more than 28 weeks of gestation, both primigravida and multigravida, elderly primi (>30 years), short statured primi (Height of $<145 \mathrm{~cm}$ ); High-risk pregnant women with history of: threatened preterm, antepartum haemorrhage, Rh incompatibility, abruptio placenta, placenta previa, malpresentations, gestational diabetes mellitus, anaemia, multiple gestation, oligohydramnios, polyhydramnios, stillbirth, intrauterine death, repeated foetal loss, foetal malformation, previous caesarean section and instrumental delivery. Written inform consent was taken from the recruited subjects and assured about confidentiality and anonymity of their responses. Formal administrative permission and Ethical Committee permission was obtained from Institutional Ethical Committee. The socio-demographic data was elicited by using Demographic proforma and biophysical parameter related information was obtained from patient's files and Likert scale was used to assess biopsychosocial wellbeing of high-risk pregnant women. Biological wellbeing variables like body image, physical activity, sleep and rest, energy and fatigue, treatment: psychological wellbeing variables like self-Identification, self-confidence, self-esteem, decision making, ambivalence, ideal versus practical confusion, inadequate abilities, liberty/ independence, fear of failure, anxiety, risk taking, coping: Social wellbeing variables like family support, influence, neglecting behaviour, hope, religiosity, economical support were included in the tool. All the data were gathered by using self-administered questionnaires and recorded by the nurse investigator. Based on obtained scores the biopsychosocial wellbeing was categorized in low and high wellbeing. The descriptive statistics in terms of frequencies and percentages was used to describe the sample characteristics and the null hypothesis was tested by computing Spearman's rho to identify relation in between biological, psychological, social wellbeing of high-risk pregnant women. The statistical level of significance was calculated at $p<0.05$ level.

\section{Result}

\section{Section I: Description of sample characteristics}

Table I.Distribution of demographic characteristics in frequency and percentages

\begin{tabular}{|c|c|c|}
\hline Demographic characteristics & $f$ & $\%$ \\
\hline \multicolumn{3}{|l|}{ Type of family } \\
\hline Nuclear family & 221 & 73 \\
\hline Joint family & 67 & 22 \\
\hline Extended family & 15 & 5 \\
\hline \multicolumn{3}{|l|}{ Religion } \\
\hline Hindu & 250 & 83 \\
\hline Muslim & 25 & 8 \\
\hline Christian & 28 & 9 \\
\hline \multicolumn{3}{|l|}{ Educational status } \\
\hline Primary education & 25 & 8 \\
\hline Secondary Education & 69 & 23 \\
\hline Higher secondary education & 122 & 40 \\
\hline Graduation & 76 & 25 \\
\hline Post-graduation & 11 & 4 \\
\hline \multicolumn{3}{|l|}{ Occupational status } \\
\hline Professional & 22 & 7 \\
\hline Homemaker & 272 & 90 \\
\hline Business & 5 & 2 \\
\hline Skilled & 4 & 1 \\
\hline \multicolumn{3}{|l|}{ Income } \\
\hline Rs. $<10000$ & 104 & 34 \\
\hline Rs. $10001-15000$ & 102 & 33 \\
\hline
\end{tabular}




\begin{tabular}{|c|c|c|}
\hline Rs. $15001-20000$ & 77 & 26 \\
\hline Rs. $>20000$ & 20 & 7 \\
\hline \multicolumn{3}{|l|}{ Parity } \\
\hline Primi & 205 & 68 \\
\hline Multi & 98 & 32 \\
\hline \multicolumn{3}{|l|}{ Area of residence } \\
\hline Urban & 116 & 38 \\
\hline Rural & 162 & 54 \\
\hline Semi urban & 25 & 8 \\
\hline \multicolumn{3}{|l|}{ Dietary habits } \\
\hline Non vegetarian & 264 & 87 \\
\hline Vegetarian & 39 & 13 \\
\hline \multicolumn{3}{|c|}{$\begin{array}{c}\text { Modes of transport from home to } \\
\text { hospital }\end{array}$} \\
\hline Own vehicle & 36 & 11 \\
\hline Walking & 44 & 15 \\
\hline Auto or bus & 223 & 74 \\
\hline \multicolumn{3}{|l|}{$\begin{array}{c}\text { Sources of Health-related } \\
\text { information }\end{array}$} \\
\hline Newspaper & 7 & 2 \\
\hline Magazines, books & 10 & 3 \\
\hline Pamphlets & 4 & 1 \\
\hline Neighbours and friends & 23 & 8 \\
\hline Television/ radio & 64 & 21 \\
\hline Family & 62 & 21 \\
\hline Health care personnel & 133 & 44 \\
\hline
\end{tabular}

Out of the 303 sampled, majority 221 (73\%) of the pregnant women with high-risk conditions were from nuclear family, 250 (83\%) belonged to the Hindu religion, 122 (40\%) were having higher secondary education, 272 (90\%) were homemakers and in most 104 (34\%) of the high-risk pregnant women, income was $<$ Rs. $10000 /$ months. Most of high-risk pregnant women 205 (68\%) were primigravida, $162(53 \%)$ were from rural area, 264 (87\%) were nonvegetarian and $223(74 \%)$ were using auto or bus to reach health centre/ hospital from home. Most of them 133 (44\%) were getting health related information from health care personnel (Table 1).

Mean age was $28.65 \pm 4.23$ years, mean period of gestation was 32.15 weeks \pm 3.08 days, mean systolic blood pressure was $115.67 \pm 9.83 \mathrm{~mm}$ of $\mathrm{Hg}$. and diastolic blood pressure was $76.23 \pm 9.22 \mathrm{~mm}$ of $\mathrm{Hg}$ (Table 2).

The distribution of the types of high-risk conditions among high-risk pregnant women is shown in Figure1, which shows that most of the high-risk pregnant women $87(26 \%)$ had previous history of abortion, 43 (13\%) had GDM, 7 (2\%) had short cervix, $7(2 \%)$ had placenta previa, $4(1 \%)$ had polyhydramnios and $4(1 \%)$ had short stature.

Table 2.Biophysical parameters of high-risk pregnant women including mean and standard deviation

\begin{tabular}{|c|c|c|}
\hline S. No. & Biophysical Parameter & Mean \pm SD \\
\hline 1. & Age (in years) & $28.65 \pm 4.23$ \\
\hline 2. & Period of gestation (in weeks) & $32.155 \pm 3.08$ \\
\hline 3. & Weight (in kg) & $60.49 \pm 10.68$ \\
\hline 4. & Height (in cm) & $155.28 \pm 6.3$ \\
\hline 5. & Amniotic Fluid Index (cm) & $13.46 \pm 2.86$ \\
\hline 6. & Haemoglobin $(\mathrm{mg} / \mathrm{dl})$ & $11.45 \pm 1.35$ \\
\hline 7. & Blood pressure $(\mathrm{mm}$ of $\mathrm{Hg})$ & \\
\hline 7a. & Systolic pressure & $115.67 \pm 9.83$ \\
\hline 7b. & Diastolic pressure & $76.23 \pm 9.22$ \\
\hline
\end{tabular}

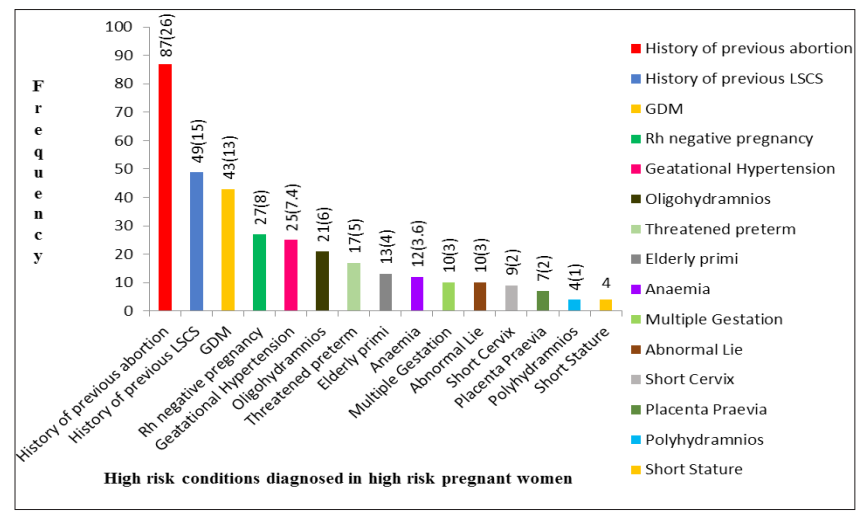

Figure I.High-risk conditions diagnosed in high-risk pregnant women

Section 2: Description of biopsychosocial wellbeing of high-risk pregnant women

Table 3.Frequency and percentage of biopsychosocial wellbeing of women with high-risk conditions

\begin{tabular}{|c|c|c|c|}
\hline Level of wellbeing & Range of score & f & $\%$ \\
\hline \multicolumn{4}{|c|}{ Biological wellbeing } \\
\hline Low wellbeing & $15-62$ & 161 & 53.1 \\
\hline High wellbeing & $63-75$ & 142 & 46.9 \\
\hline \multicolumn{4}{|c|}{ Psychological wellbeing } \\
\hline Low wellbeing & $20-79$ & 148 & 48.8 \\
\hline High wellbeing & $80-100$ & 155 & 51.2 \\
\hline \multicolumn{4}{|c|}{ Social wellbeing } \\
\hline Low wellbeing & $15-71$ & 172 & 56.76 \\
\hline High wellbeing & $72-75$ & 131 & 43.23 \\
\hline
\end{tabular}


Among the 303 pregnant women with high-risk condition, 161 (53.1\%) had low biological wellbeing and 142 (46.9\%) had high biological wellbeing; 148 (48.8\%) had low psychological wellbeing and 155 (48.8\%) had high psychological wellbeing; 172 (56.76\%) had low social wellbeing and 131 (43.23\%) had high social wellbeing (Table 3).

Section 3: Relationship between biological, psychological, social wellbeing

Table 4.Relationship among biological, psychological, social wellbeing

( $n=303)$

\begin{tabular}{|c|c|c|}
\hline Variables & Spearman's $\mathbf{p}$ & $\mathbf{p}$-value \\
\hline $\begin{array}{c}\text { Biological and psychological } \\
\text { wellbeing }\end{array}$ & 0.56 & $<.000$ \\
\hline $\begin{array}{c}\text { Biological and Social } \\
\text { wellbeing }\end{array}$ & 0.245 & $<.000$ \\
\hline $\begin{array}{c}\text { Social and Psychological } \\
\text { wellbeing }\end{array}$ & 0.391 & $<.000$ \\
\hline
\end{tabular}

There was a moderate relation between biological and psychological wellbeing which was statistically significant $(p=0.56, p=<0.00)$. There was a low relation between biological and social wellbeing which was statistically significant $(\rho=0.245, p=<0.00)$ and there was a low relation between social and psychological wellbeing which was statistically significant $(\rho=0.391, p=<0.00)$ (Table 4).

\section{Discussion}

\section{Description of the sample characteristics}

The present study findings shows that majority of women with high-risk condition 221 (73\%) were from nuclear family, 250 (83\%) belonged to Hindu religion, 122 (40\%) were having higher secondary education, 272 (90\%) were homemakers, 104 (34\%) income was Rs. <10000/month. Most of high-risk pregnant women 205 (68\%) were primigravida, 162 (53\%) were from rural area, 264 (87\%) were non-vegetarian and 223 (74\%) were using auto or bus to reach health centre/ hospital from home. Most of them 133 (44\%) were getting health related information from health care personnel (Table 1).

The finding of the present study is supported by a descriptive survey study done in North East Turkey to find out the psychological health status of pregnant women as compared to unplanned/ risk pregnancy, domestic violence, and some demographic variables such as educational status, marital status. Results revealed that antenatal women were screened in clinical setting at an average 34 weeks of gestational age with a range of 8-41 weeks of gestation, mean age $28.18 \pm 6.34$ years (range $18-34$ years). $34.3 \%$ (47) were primary school graduates, $76.6 \%$ (105) were unemployed and 70.1 (96) had nuclear family structure. The majority of $81 \%$ (111) pregnant women were living in town. ${ }^{4}$

The presents study findings reveals that the mean age was $28.65 \pm 4.23$ years, mean period of gestation was 32.15 weeks \pm 3.08 days, mean weight of high-risk pregnant women was $60.49 \pm 10.68 \mathrm{~kg}$., mean height of high-risk pregnant women was $155.28 \pm 6.3 \mathrm{~cm}$, mean amniotic fluid index was $13.46 \pm 2.86 \mathrm{~cm}$, and mean haemoglobin was $11.45 \pm 1.35 \mathrm{mg} / \mathrm{dl}$. Mean systolic blood pressure was $115.67 \pm 9.83 \mathrm{~mm}$ of $\mathrm{Hg}$. and diastolic blood pressure was $76.23 \pm 9.22 \mathrm{~mm}$ of $\mathrm{Hg}$ (Table 2).

The present study findings are supported by another crosssectional study among 450 antenatal mothers to assess relationship between social support and perceived stress at health care centre and descriptive statistics revealed that the mean (SD) of participants' age was (35 \pm 1.1$)$ years and gestational age was $(26.5 \pm 3.86)$ weeks. $35 \%$ of the participants had elementary education, $92.8 \%$ of the pregnant women were housewife. ${ }^{7}$

The present study finding shows that among the 303 pregnant women with high-risk condition 161 (53.1\%) had low biological wellbeing and 142 (46.9\%) had high biological wellbeing; 148 (48.8\%) had low psychological wellbeing and 155 (48.8\%) had high psychological wellbeing; 172 (56.76\%) had low social wellbeing and 131 (43.23\%) had high social wellbeing (Table 3).

The present study findings are also supported by a cross sectional descriptive correlation design study to assess whether prenatal coping strategies mediated the effects of uncertainty and social support on the psychological wellbeing of high-risk pregnant women. And study results showed that there was negative correlation i.e. higher level of uncertainty reported less social support $(r=-0.45, p<0.01)$ as well as less psychological wellbeing $(r=-0.30, p<0.01){ }^{8}$

The present study finding shows moderate relationship between biological and psychological wellbeing which was statistically significant $(\rho=0.56, p=<0.00)$. There was a low relation between biological and social wellbeing which was statistically significant $(\rho=0.245, p=<0.00)$ and there was a low relation between social and psychological wellbeing which was statistically significant $(\rho=0.391, p=<0.00)$ (Table 4).

The present study findings are also supported by a crosssectional descriptive study done to identify GDM with symptoms of depression compare to than women without GDM. Out of 135 pregnant women with GDM 65 women had a history of depression (23\%) compare to women without GDM (9\%) with statistically significant difference $\left(\chi^{2}=5.40\right.$, $p=0.02)$. the study concluded that women with GDM had more chances to have a history of depression than women 
without GDM (OR=3.79, 95\% Cl [1.07, 13.45], p=0.04). ${ }^{6}$

The present study findings are also supported by a crosssectional study done among 1,447 pregnant women to find out relationship between the absence of physical activity and the occurrence of mental health in pregnant women in the Northeast of Brazil and result revealed that there was association between physical inactivity $(p=0.039)$ and symptoms of severe depression .There was no association between physical inactivity and perceived stress ( $p=0.115)$. There was significant association between physical inactivity and mild $(\mathrm{OR}=1.44)$ or normal anxiety levels (OR=1.46; $p=0.008)$. The study concluded there was no significant association between perceived stress, symptoms of depression and physical inactivity. ${ }^{5}$

\section{Conclusion}

As high-risk factors cause significant changes in biological, psychological, social wellbeing of high-risk pregnant women, health care personnel need to identify the impact of highrisk factors on the biological, psychological and social wellbeing and need to plan, implement and evaluate strategies to increase the wellbeing. The ultimate goal of nursing research is to bring out evidence which can help to bring abreact quality care to improve the life of high-risk pregnant women.

\section{Acknowledgment}

I would also like to express my heartfelt gratitude and indebtedness to my respected guide Dr Sonia R B D'Souza, my co-guide, Mrs Sushmitha Karkada, Assistant Professor, Dr Judith Norhona, Associate Dean, Dr Anice George, Dean for constant encouragement and support. I thank the Institutional Ethics Committee, for providing the ethical clearance \& Dr (Col) M Dayananda, Medical Superintendent and Chief Operating Officer, Kasturba Hospital, Manipal for granting me the administrative permission to conduct the research study. My sincere thanks to the In-charge sisters, all the Staff Nurses of the antenatal wards and OBG OPDs and all the faculty members for supporting and helping me in my study.

\section{Conflict of Interest: None}

\section{References}

1. Suguna S, Kusumadevi MS. Blood Pressure values among primi and multigravida women in a rural population of Karnataka state. Journal of Evaluation Mental and Dental Sciences 2015; 4(23): 3920-3924. [Google Scholar].

2. Jain S, Anand S, Aherwar R. High-risk for prediction of pregnancy outcome: a prospective study. International Journal of Reproduction, Contraception, Obstetrics and Gynaecology 2014; 3(3): 516-522. Available from: https://www.ijrcog.org/index.php/ijrcog/article/ view/984 [Google Scholar].

3. Firozi S. The rate of the prevalence's of highrisk pregnancies and the results on pregnant mothers and the effect on parameters after the birth. Internal Journal of Pharmacological Science Research 2012; 3(10): 3735-3741. Available from: http://citeseerx.ist.psu.edu/viewdoc/download ?doi=10.1.1.300.97\&rep=rep1\&type=pdf [Google Scholar].

4. Yilmaz EB, Küçük E. Unplanned and risk pregnancy, domestic violence and the psychosocial health status of pregnant women in North-East Turkey. International Journal of Caring Sciences 2015; 8(3): 585-593. Available from: https://pdfs.semanticscholar.org/ d11e/4fdc3851c952dd3193c6115f718fe3c490e7.pdf [Google Scholar].

5. Takahasi EHM. Mental health and physical inactivity during pregnancy: a cross sectional study nested in the BRISA cohort study. Cad Saude Publication, Riode Janerio 2013; 29(8): 1583-1594. Available from: http://www.scielo.br/scielo.php?script=sci_ arttext\&pid=S0102-311X2013000800011\&lng=en\&n rm=iso\&tlng=en [PubMed/ Google Scholar].

6. Byrn M, Penckofer S. The relationship between gestational diabetes and antenatal depression. Journal of Obstetric, Gynecologic and Neonatal Nursing 2014; 44(2): 246-255. Available from: https://www.jognn. org/article/S0884-2175(15)31784-6/fulltext [PubMed/ Google Scholar].

7. Iranzad I, Bani S, Mirghafourvand M. Perceived social support and stress among pregnant women at Health Centers of Iran- Tabriz. Journal of Caring Sciences 2014; 3(4): 287-295. [PubMed/ Google Scholar].

8. Giurgescu C, Penckofer S, Maurer M, et al. Impact of uncertainty, social support and prenatal coping on the psychological wellbeing of high-risk pregnant women. Nurses Research 2006; 55(5): 356-365. Available from: https://journals.Iww.com/nursingresearchonline/ Abstract/2006/09000/Impact_of_Uncertainty,_Social_ Support,_and.8.aspx [PubMed/Google Scholar]. 